\title{
Vax1 is a novel homeobox-containing gene expressed in the developing
} \section{anterior ventral forebrain}

\author{
Marc Hallonet ${ }^{1}$, Thomas Hollemann ${ }^{2}$, Roland Wehr ${ }^{1}$, Nancy A. Jenkins ${ }^{3}$, Neal G. Copeland ${ }^{3}$, Tomas Pieler ${ }^{2}$ \\ and Peter Gruss ${ }^{1, *}$ \\ ${ }^{1}$ Max Planck Institut for Biophysical Chemistry, Department of Molecular and Cell Biology, Am Fassberg 11, 37077 Göttingen, \\ Germany \\ 2University of Göttingen, Department of Developmental Biochemistry, Humboldtallee 23, 37073 Goettingen, Germany \\ 3Mammalian Genetics Laboratory, ABL-Basic Research Program, NCl-Frederick Cancer Research and Development Center, \\ Frederick, MD 21702, USA \\ *Author for correspondence (e-mail: pgruss@gwdg.de)
}

Accepted 30 April; published on WWW 23 June 1998

\section{SUMMARY}

The vertebrate forebrain is formed at the rostral end of the neural plate under the regulation of local and specific signals emanating from both the endomesoderm and neuroectoderm. The development of the rostral and ventral forebrain in particular was difficult to study, mainly because no specific markers are available to date. Here, we report the identification of Vax1, a novel homeoboxcontaining gene identified in mouse, Xenopus and human. It is closely related to members of the Not and $\operatorname{Emx}$ gene families, all of which are required for the formation of structures where they are expressed. In mouse and Xenopus, Vax1 expression first occurs in the rostral neural plate, in the medial anterior neural ridge and adjacent ectoderm. Later, at midgestation in the mouse and tadpole stage in Xenopus, the expression remains confined in the derivatives of this territory which differentiate into rostromedial olfactory placode, optic nerve and disc, and anterior ventral forebrain. Together, these observations suggest that Vaxl could have an early evolutionary origin and could participate in the specification and formation of the rostral and ventral forebrain in vertebrates.
Comparison of the limits of the expression territory of Vax1 with that of Dlx1, Pax6 and Emx1 indicates that the corticostriatal ridge is a complex structure with distinct identifiable genetic compartments. Besides, the study of Vax1 expression in Pax6-deficient homozygous brains indicates that its regulation is independent of Pax6, although the expression patterns of these two genes appear complementary in wild-type animals. Vax1 chromosomal location is mapped at the distal end of the mouse chromosome 19, linked with that of Emx2. These two genes may have arisen by tandem duplication. The Vax 1 gene is thus an interesting new tool to study the rostral ventral forebrain patterning, morphogenesis and evolution as well as the terminal differentiation of the forebrain in mouse and Xenopus.

Key words: Emx, Not1, Pax6, Dlx1, Brain patterning, Homeobox, Neural differentiation, Forebrain, Olfactory placode, Anterior neural ridge, Ganglionic eminence, Xenopus

\section{INTRODUCTION}

The function of the brain is based on its complex subdivision in regions and nuclei anatomically and histologically distinguishable. This elaborate organization is progressively built during ontogenesis at the rostral level of the developing central nervous system (CNS). Specific genetic mechanisms control the formation of the rostral part of the neural plate and, in particular, of the forebrain. For instance, the Emx and Otx homeobox-containing genes are only expressed rostrally to the hindbrain during early steps of neurulation whereas the Hox genes, absent from the forebrain and midbrain, are only expressed in the hindbrain and spinal cord (Simeone et al., 1992a,b, 1993; Finkelstein and Boncinelli, 1994; Krumlauf et al., 1994; see Thor, 1995; Lufkin, 1996). Moreover, mouse embryos homozygous for targeted null mutation of the Otx2 homeobox-containing gene, or of the Liml zinc-fingercontaining gene, lack head structures but have the remaining body axis normally developed (Acampora et al., 1995; Matsuo et al., 1995; Pannese et al., 1995; Shawlot and Behringer, 1995; Ang et al., 1996). Accordingly, the genetic mechanisms regulating the formation of the head and of the so-called trunkal structures are relatively distinct and independent. Besides, the rostral part of the neural plate is under the influence of specific inducing/organizing centers. In particular, the axial mesoderm in contact with the neural plate, namely the prechordal mesoderm at the most anterior level and the notochord at more caudal levels, have distinct neural inducing properties on the 
adjacent developing CNS primordium (see Spemann and Mangold, 1924; Hamburger, 1988; Saha and Grainger, 1992; Doniach, 1993; Ruiz i Altaba, 1994; Ericson et al., 1996; Lumsden and Krumlauf, 1996; Dale et al., 1997). Moreover, specific and local neurectodermal signals are necessary for the formation of forebrain structures (Ang et al., 1994; Thomas and Beddington, 1996). In particular, the anterior neural ridge or the FGF8 molecule produced at this level regulates the expression of the BF1 transcription factor essential for ventral forebrain and eye formation (Shimamura and Rubinstein, 1997). Similarly, the existence of an early anterior neural boundary organizer required for normal development of the forebrain has been demonstrated in zebrafish (Houart et al., 1998). Inhibition of both the Wnt and Bmp signalings, possibly by the cerberus protein, promotes head formation as opposed to trunk formation in Xenopus (Bouwmeester et al., 1996; Glinka et al., 1997). The developing forebrain is thus under the influence of local and specific signals emanating from the neuroectoderm and endomesoderm. However, despite recent advances, the genetic mechanisms regulating the induction and the early regionalization of the ventral forebrain remain largely obscure.

In order to study the genetic mechanisms of forebrain induction and specification, we identified a new homeoboxcontaining gene with high sequence homology with the members of the Emx and Not homeobox-containing gene families. The mouse and Xenopus genes share a high sequence homology and a similar pattern of expression during neurulation. These two genes could thus be truly orthologous. Expression is first detected in the rostral and medial neural plate and anterior neural ridge. Later, at midgestation in the mouse and at the tadpole stage in Xenopus, the expression remains confined in the ventral forebrain deriving from this territory, as predicted by fate maps, and could accordingly reveal a developmental unit. In addition, high sequence homology between Vaxl and Notl and Emx genes suggest that it could function in the specification and formation of the rostral and ventral forebrain structures. Vaxl chromosomal location, sequence homology and pattern of expression in a phylogenetically ancient part of the forebrain lead us to conclude that Vaxl represents a new interesting tool to study the ventral forebrain induction, morphogenesis and evolution.

\section{MATERIALS AND METHODS}

\section{Isolation of the Vax1 cDNA}

A 180 bp DNA fragment containing the homeobox-coding sequence of the chicken Not1 gene (Stein and Kessel, 1995) was used to hybridize a mouse E14.5 brain library (see Oliver et al., 1995; Wijnholds et al., $1995)$ at $65^{\circ} \mathrm{C}$ in $10 \times$ Denhardt's, $5 \times$ SSC, $0.1 \%$ SDS. Filters were rinsed three times at low stringency $\left(20\right.$ minutes at $60^{\circ} \mathrm{C}$ in $1 \times \mathrm{SSC}$, $0.1 \%$ SDS). A partial cDNA clone, cf5, containing the coding region of the mouse Vaxl homeobox was isolated and used to screen the same library under more stringent conditions (hybridization in the conditions described above, followed by three rinsings for 20 minutes at $65^{\circ} \mathrm{C}$ in $0.1 \times \mathrm{SSC}, 0.1 \%$ SDS). We finally isolated a cDNA clone of $1.6 \mathrm{~kb}$ containing the mouse Vax 1 putative full coding sequence.

Degenerated primers were used to amplify Xenopus Vaxl-related sequences (primer P1 5'CGGAATTCCGTGGAICTGGACCGGCCCAAG and primer P2 5'TGCTCTAGAGCTTCACCTGGGTCTCGGAGAG) from 30 aliquots of a stage 32 head cDNA library containing $1.5 \times 10^{6} \mathrm{pfu}$ in total $(30 \times 50.000 \mathrm{pfu})$ in a final volume of $25 \mu \mathrm{l}$ as previously described (Hollemann et al., 1998). The PCR products were directly sequenced using the $\mathrm{ABI}$ cycle sequencing kit
(USB). Screening of amplified cDNA libraries was performed as described with the degenerate primers specified above (Israel, 1993). Three rounds of PCR were performed to rescreen increasing dilutions of the stock library. Finally, 12 positive phage clones containing identical inserts with putative full coding sequence were isolated.

\section{Quantitative RT-PCR analysis}

RNA from oocytes and embryos and from tissues of adult frogs was extracted as described previously (Hollemann et al., 1998). RT-PCR analysis was carried out using the Gene Amp RT-PCR kit from PerkinElmer Cetus. First-strand cDNA was synthesized using $1 \mu \mathrm{g}$ RNA from the various embryonic stages indicated and tissues with random hexanucleotides as primers. Initial denaturation was performed for 3 minutes at $95^{\circ} \mathrm{C}$, followed by 40 amplification cycles $\left(1\right.$ minute, $95^{\circ} \mathrm{C}$; 1.5 minute, $52^{\circ} \mathrm{C} ; 1.5$ minute, $72^{\circ} \mathrm{C}$ ) and a final polymerization step (10 minutes, $\left.72^{\circ} \mathrm{C}\right)$.

For quantitative RT-PCR, first-strand cDNA was synthesized from $0.5 \mu \mathrm{g}$ RNA as described above. Amplification was done in a $100 \mu \mathrm{l}$ reaction containing the appropriate primer mix for XVaxl (P3 corresponding to amino acid 161-177 5'AGGAGCAGCCGGGAACTTAC and P4 corresponding to amino acid 275-281 5'TCTCTGCCGACCAAATACTGTC resulting in a DNA product of 364 nucleotides), and Histone $\mathrm{H} 4$ as previously described. The linear range of amplification was determined by carrying out PCR including $0.5 \mu \mathrm{g}$ of RNA of stage 32 embryos and $1 \mu \mathrm{Ci}$ of alpha- ${ }^{32} \mathrm{P}-\mathrm{dCTP}$ with increasing numbers of PCR cycles. Amplification was linear up to cycle number 30 . Amplification of XVaxl transcripts was done for 28 cycles and amplification of histone $\mathrm{H} 4$ transcripts for 23 cycles. One tenth of each PCR product was analyzed on a $6 \%$ polyacrylamide gel under denaturing conditions. As a size marker $\alpha-{ }^{32} \mathrm{P}$-end-labelled $1-\mathrm{kb}$ ladder (Gibco) was used. Dried gels were analyzed using a PhosphorImager and the ImageQuant 2.0 program (Molecular Dynamics).

\section{In situ analysis}

In situ hybridization experiments, on paraffin sections with radiolabelled probes or whole embryos with DIG-labelled probes, were performed as previously described on NMRI mouse material (Wilkinson, 1992; Stoykova and Gruss, 1994). We used clone cf5 cut with HindIII or XhoI and transcribed with SP6 or T7 RNA polymerase for Vaxl sense or antisense probes, respectively. A Pax6 clone, spanning from the 3' part of the homeobox to the $3^{\prime}$ untranslated region, cut with BamHI or HindIII and transcribed with T3 or T7 RNA polymerase was used for antisense or sense probes respectively. Dlxl, Emxl and Emx2 probes were prepared as previously described (Price et al., 1991; Simeone et al., 1992b). In order to test possible regulation of Vaxl expression by the Pax6 gene product, in situ hybridization experiments were also performed on Pax6-deficient embryos from either the classical sey mutants (Roberts, 1967; Hogan et al., 1986), or from animals carrying an experimentally inactivated Pax6 gene (StOnge et al., 1997). Homozygous embryos were selected on the basis of their eye size as previously described (Stoykova et al., 1996).

Whole-mount in situ hybridization of Xenopus embryos was performed as described by Harland (1991). Digoxigenin-UTP RNAprobes were used and developed with NBT/BCIP (Boehringer). For plastic sections, embryos were stained for 3 days at $6^{\circ} \mathrm{C}$, embedded in Technovit 7100 (Kulzer), sectioned $(6 \mu \mathrm{m})$ and mounted in Entellan (Merck). Photographs were taken on a Zeiss Axioskop using Nomarski interference optics.

\section{Interspecific mouse backcross mapping}

Interspecific backcross progeny were generated by mating (C57BL/6J $\times M$. spretus) $\mathrm{F}_{1}$ females and C57BL6/6J males as described (Copeland and Jenkins, 1991). A total of 205 N2 mice was used to map the Vaxl locus (see text for details). DNA isolation, restriction enzyme digestion, agarose gel electrophoresis, Southern blot transfer and hybridization were performed essentially as described (Jenkins et al., 1982). The probe, a 460 bp BamHI 5' cDNA fragment excluding 
the homeobox coding region, was labelled with alpha- ${ }^{32} \mathrm{P}-\mathrm{dCTP}$ using a random primed labeling kit (Stratagene); washing was done to a final stringency of $1.0 \times \mathrm{SSCP}, 0.1 \% \mathrm{SDS}, 65^{\circ} \mathrm{C}$. A fragment of $13.5 \mathrm{~kb}$ was detected in SacI-digested C57BL6/6J DNA and a fragment of 7.3 kb was detected in SacI-digested M. spretus DNA.

A description of the probes and RFLPs for two of the loci linked to Vaxl including Mxil and Aopl has been reported previously (Juan et al., 1997) Three loci have not been reported previously for this interspecific backcross. The probe for Pax 2 was an $\sim 1.7 \mathrm{~kb}$ BamHI/EcoRI fragment of mouse cDNA that detected TaqI fragments of 4.6, 0.6 and $0.4 \mathrm{~kb}$ in C57BL6/6J (B) DNA and 5.4, 4.6, 0.6 and $0.4 \mathrm{~kb}$ in M. spretus. (S) DNA. The probe for $F g f 8$, an $\sim 800$ bp SmaI-XhoI fragment of mouse cDNA, detected PstI fragments of 2.1, 1.3 and 1.1 (B), and 2.1, 1.1 and $0.9(\mathrm{~S}) \mathrm{kb}$. This probe also detected HindIII fragments of 8.1 and 3.2 (B) and 20.5 and 3.2 (S) kb. The PstI and HindIII data were combined. Finally, the probe for Emx2 was an $\sim 1.1 \mathrm{~kb} X h o$ I fragment of mouse genomic DNA that detected $B g$ III fragments of 8.2 and 3.2 (B) and 8.6 and $2.4(\mathrm{~S}) \mathrm{kb}$. In each case, the inheritance of $M$. spretus-specific fragments was followed in backcross mice. Recombination distances were calculated using Map Manager, version 2.6.5.

\section{RESULTS}

\section{Isolation and characterization of the mouse and Xenopus Vax1 sequence}

In an attempt to identify new murine genes related to the Not sub-group of homeobox-containing genes (see Duboule, 1994), we used the chicken Not1 homeobox coding region to probe a mouse brain E14.5 cDNA library at low stringency (Wijnholds et al., 1995). We finally isolated a cDNA clone of approximately $1.6 \mathrm{~kb}$ containing a putative open reading frame coding for a new 338 amino acids long homeobox-containing gene (Fig. 1A).

Sequence comparison identified a human EST clone (GenBank accession number H92142) containing an unspliced intron inside the region coding for a homeodomain identical to that of Vaxl (see Fig. 1B).

The murine Vaxl gene being expressed in a phylogenetically ancient and evolutionarily conserved part of the ventral forebrain suggested that this gene could also exist in lower vertebrate. We thus used the mouse and human sequences in order to design primers to isolate the Xenopus homologous gene using PCR. The putative full-length XVax 1 cDNAs has been isolated as detailed in Materials and Methods. The predicted amino acid sequence shares $71 \%$ homology with the mouse total sequence, and $95 \%$ at the level of the homeodomain (Fig. 1). In addition, both the mouse and Xenopus sequences share two putative translation initiation codons at

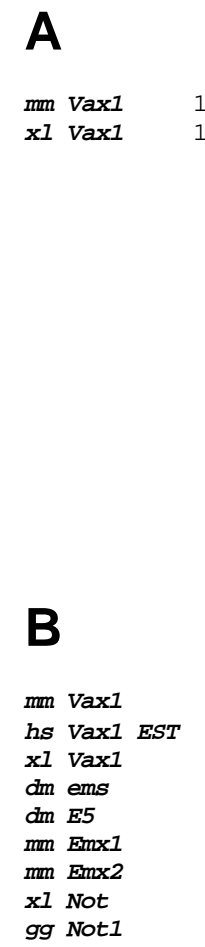

identical positions (see Fig. 1A) (Kozak, 1986; Cavener and Ray, 1991; Boek and Kolakofsky, 1994).

The high degree of conservation in the homeodomain required for sequence-specific DNA binding suggests that the Vaxl genes binds to a highly conserved binding site. The predicted homeobox amino acid sequences share high homology with the Notl genes and with the empty spiracles related genes (Fig. 1B). However, the YPW conserved amino acid residues present in all the Emx genes upstream of the homeobox (Simeone et al., 1992b) are absent from the mouse and Xenopus sequences (Fig. 1A).

\section{Chromosomal location of Vax1}

The mouse chromosomal location of Vaxl was determined by interspecific backcross analysis using progeny derived from matings of $\left[(\mathrm{C} 57 \mathrm{BL} / 6 \mathrm{~J} \times\right.$ Mus spretus $\left.) \mathrm{F}_{1} \times \mathrm{C} 57 \mathrm{BL} / 6 \mathrm{~J}\right]$ mice. This interspecific backcross mapping panel has been typed for over 2000 loci that are well distributed among all autosomes as well as X chromosome (Copeland and Jenkins, 1991). C57BL6/6J and M. spretus DNAs were digested with several enzymes and analyzed using Southern blot hybridization for informative restriction fragment length polymorphisms (RFLPs) using a mouse cDNA Vaxl probe. The $7.3 \mathrm{~kb}$ SacI $M$. spretus RFLP (see Materials and Methods) was used to follow

1 MFGKPDKMDVRCHSDTEAARVSKNAHKESREIKGAEGSLPAAFLKEPQGAFSGSGASEDC M-E-TTD--I--NIE.-NG-I-- . P-DNK---ETQAKM-STY---QP-TYPAP-S--LNKSKSNSSADPDYCRRILVRDAKGS IREI ILPKGLDLDRPKRTRTSFTAEQLYRLEMEFQ A-N--S-AG--E------------------------------S----------------RCQYVVGRERTELARQLNLSETQVKVWFQNRRTKQKKDQGKDSELRSVVSETAATCSVLR

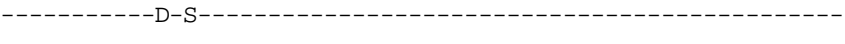
LLEQGRLLSPPGLPALLPPCATGALGSALRGP SLPALGAGAAAGSAAAAAAAAAATAPGP AGAASQHQPAVGGAPGPGPAGPGGLHAGAPTASHGLFSLPVPSLLGSVASRLSSAPLTMA S-PGTRSLAT-TST-PHQ- . . . ---PSP . . TG-NI-NM--------T--N-----H----GSLAGNLQELSARYLSSSAFEPYSRTNNKEGAEKKALD $338 \quad$ ID - . . . --H-----------------SIS-DSLD--L-- $295 \quad 71 \%$

Fig. 1. (A) Vaxl mouse and Xenopus amino acid sequence comparison. GenBank accession numbers for Vaxl sequences are AF064554 and AF064601. (B) Mouse and Xenopus Vax1 homeodomain amino acid sequence alignment in comparison to the homeodomain of Drosophila (dm) ems, Homo sapiens ( $h s)$, mouse ( $m m$ ) Emxl and Emx2, Xenopus ( $x l$ ) and chicken $(g g)$ Not1. Identical amino acids are represented by hyphens. Dots represent gaps introduced in the amino acid sequence in order to obtain optimal alignment. Identity (ID) values were calculated pairwise. The human and mouse Emx homeobox amino acid sequences are identical. Only the mouse sequences are thus presented. The underlined amino acid of the mouse Vaxl sequence indicate the predicted positions of the three helixes of the homeodomain. The intron sequence between position $44(\mathrm{Q})$ and $45(\mathrm{~V})$ within the third helix of the homeobox of the human EST clone sequence has been removed from the sequence in this figure. 


\section{A}

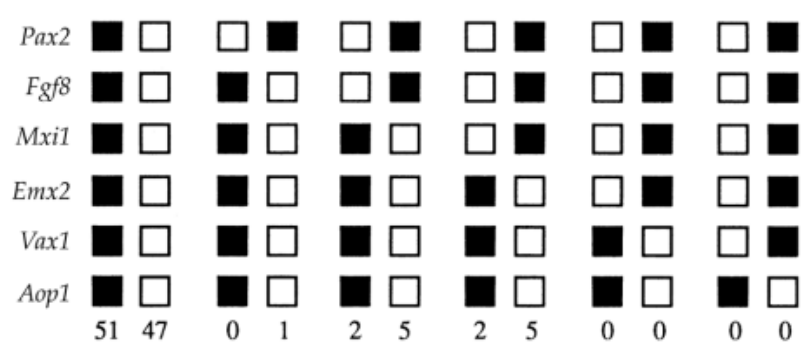

B

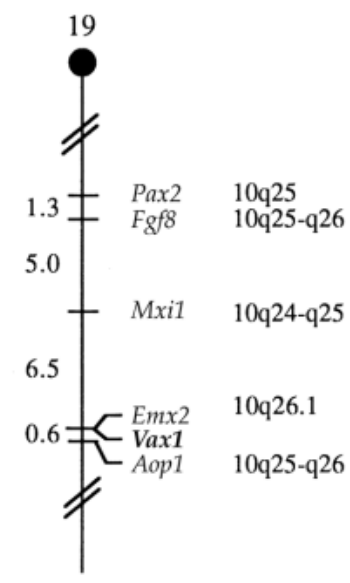

Fig. 2. Vaxl is mapped in the distal region of mouse chromosome 19. (A) Vaxl was placed on mouse chromosome 19 by interspecific backcross analysis. The segregation patterns of Vaxl and flanking genes in 113 backcross animals that were typed for all loci are shown at the top of the figure. For an individual pair of loci, more than 113 animal were typed (see text). Each column represents the chromosome identified in the backcross progeny that was inherited from the $(\mathrm{C} 57 \mathrm{BL} / 6 \mathrm{~J} \times M$. spretus $) \mathrm{F}_{1}$ parent. The shaded boxes represent the presence of a $\mathrm{C} 57 \mathrm{BL} / 6 \mathrm{~J}$ allele and white boxes represent the presence of a $M$. spretus allele. The number of offspring inheriting each type of chromosome is listed at the bottom of each column. (B) A partial chromosome 19 linkage map showing the location of Vaxl in relation to linked genes. Recombination distances between loci in centimorgans are shown to the left of the chromosome and the positions of the loci in human chromosomes, where known, are shown to the right. References for the human map positions of loci cited in this study can be obtained from GDB (Genome DataBase), a computerized database of human linkage information maintained by the William $\mathrm{H}$. Welsh Medical Library of The John Hopkins University (Baltimore, MD).

the segregation of the Vaxl locus in backcross mice. The mapping results indicated that Vaxl is located in the distal region of the mouse chromosome 19 linked to Pax2, Fgf8, Mxi1, Emx2 and Aop1. Although 113 mice were analyzed for every marker and are shown in the segregation analysis (Fig. 2), up to 169 mice were typed for some pairs of markers. Each locus was analyzed in pairwise combinations for recombination frequencies using additional data. The ratios of the total number of mice exhibiting recombinant chromosomes to the total number of mice analyzed for each pair of loci and the most likely gene order are: centromere - Pax2 - (2/154) Fgf8 - (8/159) - Mxi1 - (11/169) - Emx2 - (0/157) - Vax1 (1/156) - Aopl. The recombination frequencies [expressed as genetic distances in centiMorgans $(\mathrm{cM}) \pm$ the standard error] are Pax 2 - (1.3 \pm 0.9$)-F g f 8-(5.0 \pm 1.7)-M x i I-(6.5-1.9)-$ [Emx2, Vaxl] - $(0.6 \pm 0.6)-$ Aopl. No recombinants were detected between Emx2 and Vaxl in 157 animals typed in common suggesting that the two loci are within $1.9 \mathrm{cM}$ of each other (upper $95 \%$ confident limit). The tight linkage and sequence relatedness between Vaxl and Emx2 suggest that the genes may have arisen by tandem duplication.

We have compared our interspecific map of chromosome 19 with a composite mouse linkage map that reports the map location of many uncloned mouse mutations (provided from Mouse Genome Database, a computerized database maintained at the Jackson Laboratory, Bar Harbor, ME). Vaxl mapped in a region of the composite map that lacks mouse mutations with a phenotype that might be expected for an alteration in this locus (data not shown).

The distal region of mouse chromosome 19 shares a region of homology with human chromosome 10q25-26 (summarized in Fig. 2) where the human $E M X 2$ has been mapped (Kastury et al., 1994). This suggests that the human homolog of Vaxl is likely to map to this region as well. Apart from Brunelli and collaborators, who found that three out of eight patients with severe schizencephaly were heterozygous for different mutations in the EMX2 gene (Brunelli et al., 1996), no other human chromosomal alterations have been reported in this region (see Online Mendelian Inheritance in Man, John Hopkins University and National Center for Biotechnology Information, World Wide Web URL: http://www.ncbi.nlm.nih.gov./Omim/).

\section{Vax1 expression pattern in the mouse}

In the mouse, the expression of Vaxl is detectable at embryonic day $8 \mathrm{pc}(\mathrm{E} 8)$, at the most rostral level of the medial neural plate, including the anterior neural ridge (ANR) and adjacent ectoderm (Fig. 3). After neural tube closure, during E9, expression is detected in the ectoderm in a transverse band located between the developing olfactory placodes, medially in contact with the neural tube (Fig. 4). Between embryonic days 10 and 12, the expression persists in the rostral oral ectoderm and in the rostral and medial part of the olfactory placodes. No clear expression was detected after E12 in the derivatives of these structures and in the vomeronasal organ in particular. From E9 to E14, the expression remains confined in the derivatives of the neural plate regions expressing the gene at E8 (Figs 4, 7 and 8) as predicted by fate maps (Couly and Le Douarin, 1987; Eagleson and Harris, 1990; Eagleson et al., 1995). They are namely the optic disk, the optic stalk and later optic nerve, the optic chiasm, the suprachiasmatic area, the hypothalamic cell cord, the whole preoptic area, the septum, the entopeduncular area and the basal ganglia. Laterally, the expression is confined to the lateral and medial ganglionic eminences (LGE and MGE respectively). Caudally, the expression is restricted in the rostral part of the anterior hypothalamus (Fig. 7). The expression in the septum does not enter the roof of the cortical telencephalon (Fig. 8).

\section{Vax1 expression pattern in the Xenopus}

Quantitative RT-PCR demonstrates that zygotic XVaxl transcription, first detectable at early gastrula stages, gradually increases until stage 38. In adult frog tissues, XVax1 expression is restricted to neural derivatives and testes (Fig. 5). Whole-mount in situ hybridization experiments demonstrate 
that, similarly to the situation in mouse, $\mathrm{XVax} 1$ is expressed in the anterior-most region of the open neural plate and midanterior and midlateral anterior ridge (stage 16, Fig. 6A). By late neurula stages (stage 19), XVax1 expression is detected in the derivatives of these regions as predicted by fate maps established in Xenopus (Eagleson and Harris, 1990; Eagleson et al., 1995), namely, in the anterior and rostral ventrolateral part of the forebrain neuroepithelium, the primordium striatum, the optic stalk, the chiasmatic ridge and the anterior hypothalamus (Fig. 6B). At tailbud stages (stage 26), the expression extends laterally and caudally with the enlargement of the forebrain ventricle (Fig. 6C). XVax1 expression in tadpole stage embryos (stage 34, Fig. 6D-H) is specific to the optic disc (Fig. 6C,D,G), the optic stalk (Fig. 6C,D,G,H), and the anterior hypothalamus (Fig. 6F).

In summary, the expression of Vaxl is strikingly similar in mouse and Xenopus embryos during early neurulation. As

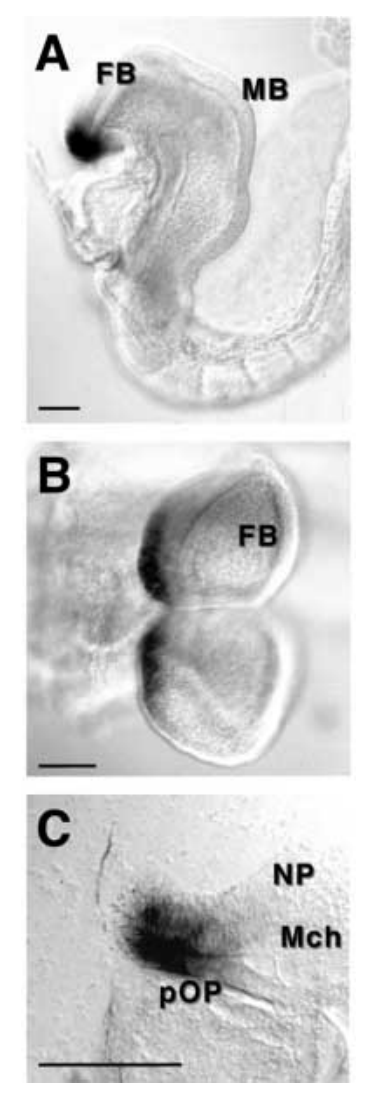

Fig. 3. Expression of Vaxl in the telencephalic neural plate and adjacent presumptive olfactory placode ectoderm at E8. (A-C) Whole-mount in situ hybridization with a DIG-labelled Vaxl probe. (A) Lateral view. The expression is restricted to the anterior end of the embryo. (B) Frontal view. The expression is restricted in the anterior border of the neural plate. (C) Lateral parasagittal vibratome section at the telencephalic level. Vaxl transcription occurs in the anterior part of the telencephalic neural plate, anterior neural ridge, and in the adjacent prospective olfactory placode ectoderm. This neuroectodermal expression domain is very limited, and does not contact the cephalic mesenchyme. It apparently does not extend to the hypophysial placode located more posteriorly. MB, midbrain region; Mch, cephalic mesenchyme; FB, forebrain region; NP, neural plate epithelium; pOP, presumptive olfactory placode ectoderm. Scale bar, $100 \mu \mathrm{m}$. expression is mainly restricted to derivatives of the anterior neural plate during early vertebrate embryogenesis, we named the gene Vaxl for ventral anterior homeobox-containing gene.

\section{Expression of Vax1, DIx1, Pax6 and Emx1 define distinct boundaries within the mouse forebrain}

In order to delineate and characterise with more precision the limits of the Vaxl expression domain, we compared Vaxl

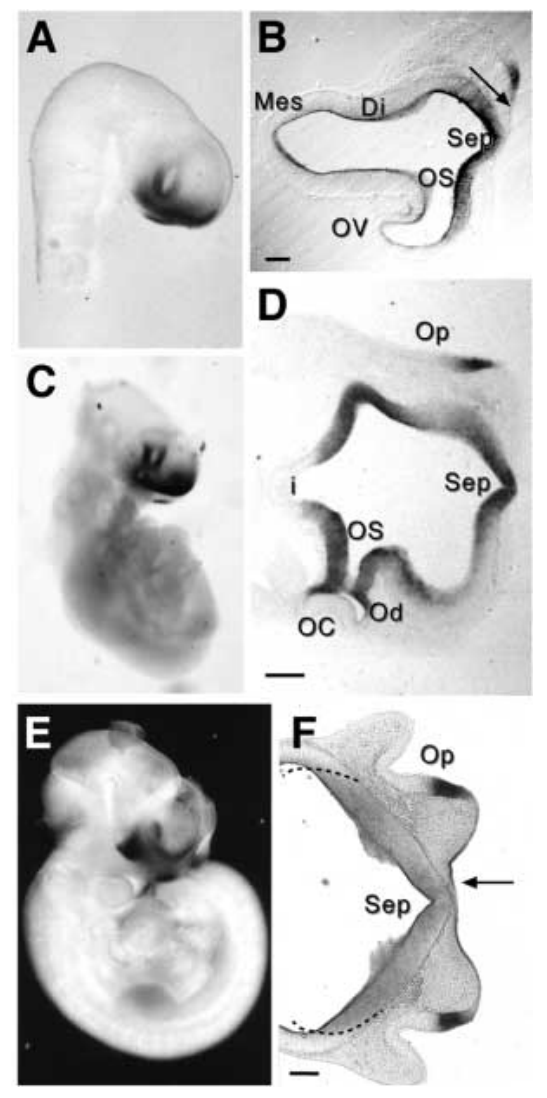

Fig. 4. Vax1 expression between E9.5 and E12.5 in the basal forebrain, optic stalk, optic disk and medial olfactory placode. Whole-mount in situ hybridization with a DIG-labelled Vaxl probe at different stages of development. (A) Lateral view at E9.5; (B) vibratome oblique coronal section through diencephalon and forebrain at E9.5. Vaxl expression is restricted in the ventral forebrain and in a medial band of ectoderm between the two developing olfactory placodes, in contact with the ventral forebrain. At this stage, expression is restricted to the rostral and ventral part of the optic stalk. Vaxl expression is also visible in the septum.

(C) Lateroventral view of Vaxl expression at E11; transcription is detected in the ventral forebrain and optic stalk. (D) Ventral coronal vibratome oblique section through the ventral forebrain at E11. The caudal and rostral part of the optic stalk express the gene. The expression is absent from the optic cup and is restricted to the optic disk and stalk. Caudally, this expression is limited at the border with the forming infundibulum (i), corresponding to the developing tuberal hypothalamus region. (E) Lateral view at E12.5; (F) coronal vibratome section showing the expression in the presumptive anterior oral ectoderm between the olfactory placodes also expressing the gene in their rostral and medial level. Dashed lines delineate the expression in the ventral forebrain. Di, diencephalon; i, developing infundibulum; Mes, mesencephalon; OC, optic cup; Od, optic disk; Op, developing olfactory placode; OS, optic stalk; OV, optic vesicle; Sep, Septal region. Scale bar, $100 \mu \mathrm{m}$. 
A
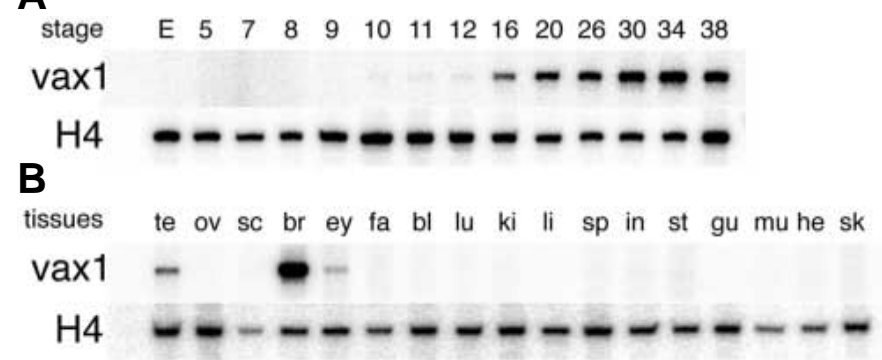

Fig. 5. Expression of $X \operatorname{Vax} 1$ during early development (stages as indicated, A) and in tissues of adult frogs (B) as detected by quantitative RT-PCR. Transcription of Xvax 1 is activated in early gastrula and upregulated during neurulation. te, testis; ov, ovary; sc, spinal cord; br, brain; ey, eye; fa, fat body; bl, bladder; lu, lung; ki, kidney; li, liver; sp, spleen; in, intestine; st, stomach; gu, gut; mu, muscle; he, heart; sk, skin.

expression pattern with that of other markers of the mouse developing forebrain. We used the Dlxl gene (Price et al., 1991; Bulfone et al., 1993) as a ventral marker and the Pax6 and Emxl genes as dorsal markers (see Walther and Gruss, 1991; Simeone et al., 1992b; Stoykova and Gruss, 1994).

The Dlxl and Vaxl genes are both expressed in the septum, preoptic area and ganglionic eminences. However, Dlxl gene expression extends more caudally and dorsally in the ventral thalamus and lateral hypothalamus in contrast to Vaxl (see Figs 7B,C,E,F, 8B,C) (see Price et al., 1991; Bulfone et al., 1993). Conversely, Vaxl is expressed in the optic chiasm and optic stalk regions where Dlxl is absent (see Figs 7E,F, 8E,F). At the level of the basal ganglia, the expression of Vaxl is restricted to the ventricular zone and the deeper part of the subventricular zone (SVZ) (Boulder Committee, 1970). At this level, Dlxl expression extends more distally outwards in the $\mathrm{SVZ}$ and is not as restricted to the deep SVZ as that of Vaxl (see Figs 7B,C, 8B,C). In addition, Vaxl expression is more restricted laterally in the LGE than Dlxl expression. Dlxl expression extends slightly more laterally in the lateral LGE than that of Vaxl toward the corticostriatal sulcus so that it nearly contacts the Emxl-expressing cortical region (Fig. 9).

Pax6 transcripts are detected as previously described (Walther and Gruss, 1991; Stoykova et al., 1996, 1997) (Figs 7A,D,G, 8A,D). As opposed to that of Emxl (see Simeone et al., 1992b), the expression of the Pax6 gene transgresses the corticostriatal boundary and extends from the cortical compartment into the lateral LGE, where it apparently abuts that of $\operatorname{Vaxl}$ (Figs 7A-E, 8A,B, 9A,B). The pattern of expression of Pax6 and Vaxl genes are thus quite complementary and exclusive in the forebrain.

\section{Vax1 gene expression in Pax6-deficient homozygous mutant mice}

We therefore further tested the possibility that Pax6 could regulate the expression of the Vaxl gene in Pax6-deficient mice. Genetic lesions of Pax6 have already been extensively documented in the rodent small eye (sey) mutants, sharing ocular and brain malformations (for references, see: Stoykova et al., 1996; Caric et al., 1997).

Studies of rodent sey mutants demonstrate the Pax6 function in forebrain patterning and regionalization (Matsuo et al.,
1993; Stoykova et al., 1996; Mastick et al., 1997). In particular, the corticostriatal boundary is impaired in Sey mice as evidenced by the $D l x l$ gene expression transgressing this boundary in homozygous mutants, but not in wild-type animals (Stoykova et al., 1996; Mastick et al., 1997). Moreover, Pax6 has a probable role in embryonic cortical cell migration (Caric et al., 1997) and in diencephalic precursor proliferation (Warren and Price, 1997).
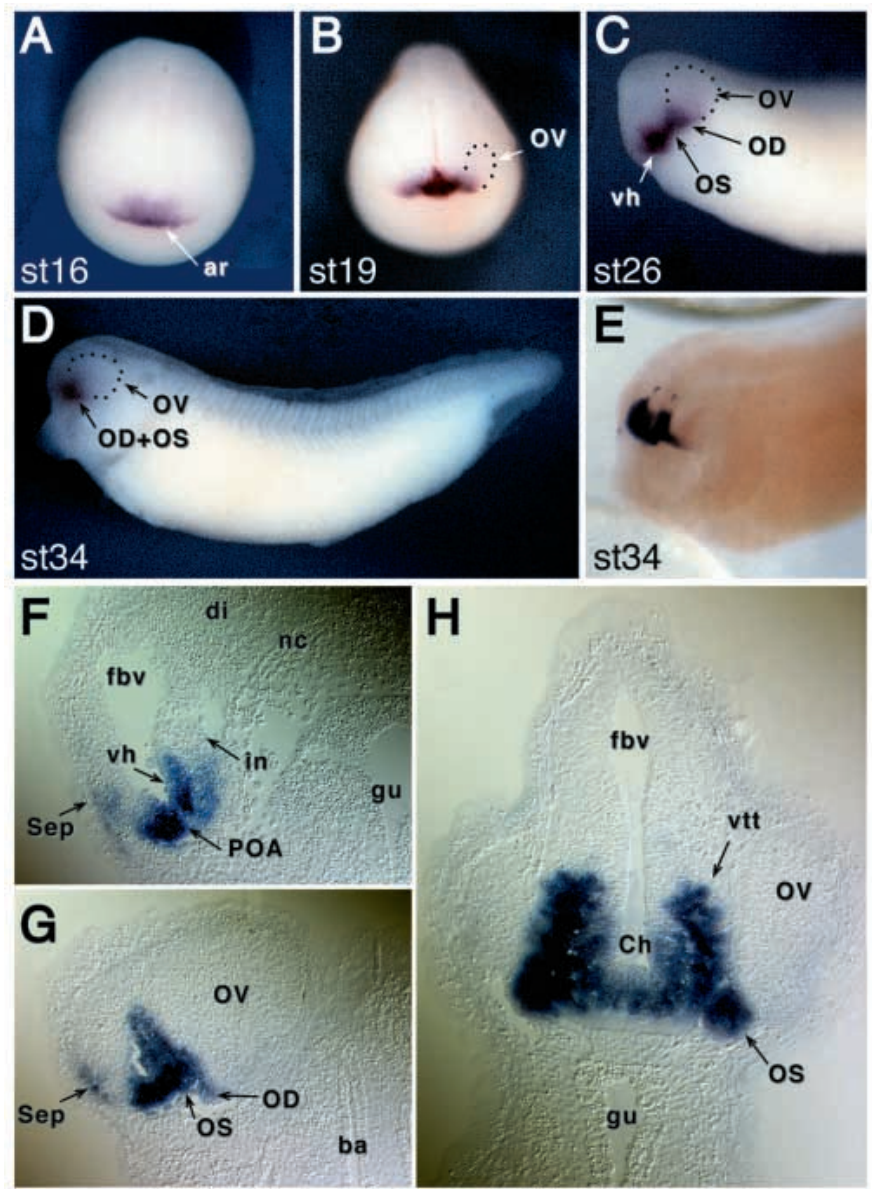

Fig. 6. Developmental expression of XVaxl analyzed by wholemount in situ hybridization. (A) Anterior view of an embryo at stage 16. Staining is detected in the anterior neural ridge. (B) Anterior view of XVaxl expression at stage 19. XVaxl signal is visible in the ventral forebrain. The optic vesicle (OV) shows no expression. (C) Ventral/anterior view of an embryo at stage 26. XVaxl transcripts are detected in the ventral hypothalamus (vh), optic stalk (OS) and the optic disc (OD). (D) Lateral view at stage 34. XVaxl transcripts are located the ventral and anterior forebrain. (E) To improve resolution, a cleared embryo at stage 34 is shown in a dorsal/lateral view. Strong $X \operatorname{Vax} 1$ expression is visible in the ventral anterior forebrain with a sharp dorsal boarder. (F-H) Sections of stained plastic embedded embryos at stage 34. F; In a sagittal section XVaxl transcripts are detected in the chiasmatic ridge and the ventral hypothalamus. (G) Parasagittal section showing XVaxl expression in the eye disc and in the optic stalk. (H) Transverse section at the level of the optic chiasm. ar, anterior ridge; ba, branchial arch; $\mathrm{Ch}$, chiasmatic ridge; di, diencephalon; fbv, forebrain vesicle; gu, gut; i, infundibulum; nc, notochord; OD, optic disk; OS, optic stalk; OV, optic vesicle; sep, septal/striatal region; vh, ventral hypothalamus; vtt, ventral tegmental tract. 
Fig. 7. Vaxl expression at E13.5 pc compared with that of Pax6 and Dlxl on horizontal sections. (A-H) In situ hybridization using radiolabelled probes, respectively, from dorsal to ventral. (A,D,G) Pax6 probe; (B,E,H) Vax1 probe; (C,F) Dlxl probe. Vaxl is expressed in the basal forebrain in the ventricular and deep subventricular zones of the septum, LGE, anterior hypothalamus, optic chiasm, optic disk and optic nerve (B,E,H), but excluding the amygdala (A,B). The observed expression of Pax6 corresponds with previous descriptions (Walther and Gruss, 1991) and confirms the presence of transcripts in the ventricular zone of the lateral LGE (A,D) and retrochiasmatic region $(\mathrm{G})$. The expression domains of Pax6 and Vaxl are exclusive, apart from the septal area. Very low Pax6 expression is also observed in the ventricular zone of the LGE (A-B; $\mathrm{D}-\mathrm{E})$. The observed expression of $D l x l$ corresponds to previous descriptions (Bulfone et al., 1993). Dlxl and Vaxl are both expressed in the septum and ganglionic eminences (B,C,E,F). However, the expression of Vaxl is more restricted in the deep subventricular zone. The dorsolateral limit of $D l x l$ expression is located slightly more laterally than that of Vaxl in the lateral LGE. In addition, the Dlxl domain of expression extends more caudally than that of Vaxl in the caudal hypothalamus and ventral thalamus. Inversely, Vaxl is expressed in the posterior preoptic area as opposed to Dlxl (B,C). AHy, adenohypophysis; Ctx, developing cerebral cortex; HCC; hypothalamic cell cord; LGE, lateral ganglionic eminence; MGE, medial ganglionic eminence; Od, optic disk; On, optic nerve; POA, anterior preoptic area; POP, posterior preoptic area; $\mathrm{RCH}$, retrochiasmatic area; SCH, suprachiasmatic area; Sep; Septum; VT, ventral thalamus. Scale bar: $1 \mathrm{~mm}$.
We used both sey and Pax6-transgenic homozygous animals (St-Onge et al., 1997) to study Vaxl expression pattern in the absence of functional Pax6 and observed similar results. In homozygous animals, the restricted $D l x l$ expression is distorted at the level of the boundary between the LGE and the developing cortex, and so-called corticostriatal boundary, so that it extends ectopically in cortical areas (Fig. 10A) as previously reported (Stoykova et al., 1996). Similarly, Vaxl expression is also shifted laterally at the level of the subventricular zone towards the cortical area. However, the lateral limit of expression of Vaxl in the ventricular zone remains more medial than that of $D l x l$ in these homozygous mutants (see arrows in Fig. 10B).
Fig. 8. Vaxl expression at E13.5 pc compared with that of Pax6 and $D l x l$ on sagittal sections. (A-F) In situ hybridization using radiolabelled probes. (A,D) Pax6 probe; $(\mathrm{B}, \mathrm{E}) \operatorname{Vax} 1$ probe; $(\mathrm{C}, \mathrm{F})$ $D l x 1$ probe. The expression domains of Pax6 and Vaxl are exclusive except in the septal area where Pax6 is expressed in the ventricular zone and Vaxl in the ventricular and deep subventricular zone (A,B). Dlxl and Vaxl both express in the septum and LGE (B,C, E,F). However, the expression of Vaxl is more restricted in the deep subventricular zone. The $D l x l$ domain of expression extends more caudally than that of Vax 1 in the caudal hypothalamus and ventral thalamus. In addition, Vaxl is expressed in the posterior preoptic area as opposed to Dlxl (B,C). AHy, adenohypophysis; Ctx, developing cerebral cortex; HCC; hypothalamic cell cord; LGE, lateral ganglionic eminence; POA, anterior preoptic area; POP, posterior preoptic area; $\mathrm{RCH}$, retrochiasmatic area; $\mathrm{SCH}$, suprachiasmatic area; Sep; Septum; VT, ventral thalamus. Scale bar: $1 \mathrm{~mm}$.

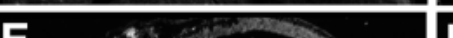

Pax6
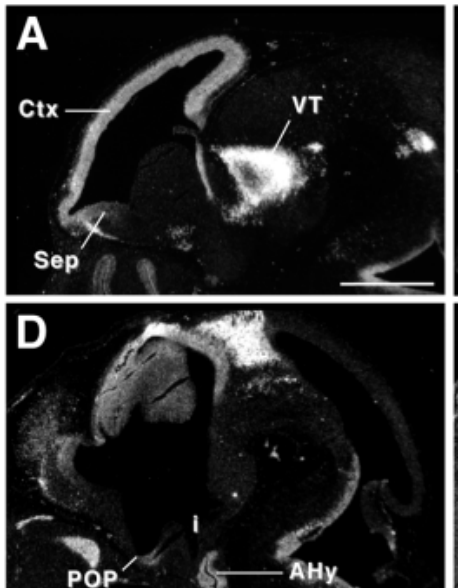

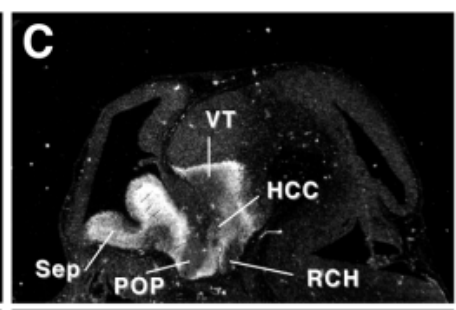

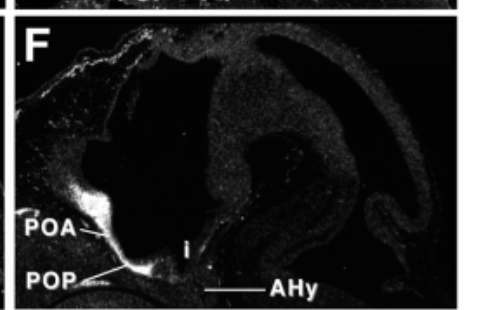



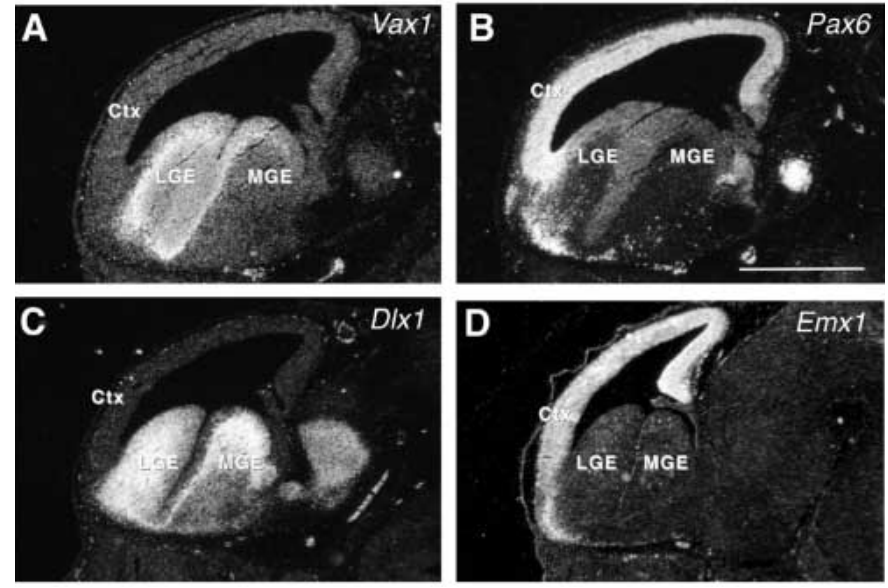

Fig. 9. The corticostriatal boundary is a complex region, located between the developing cortex and LGE, where distinct limits of various gene expression are identifiable. (A-D) In situ hybridization on lateral sagittal sections with $\operatorname{Vax} 1$ (A), Pax6 (B), Dlx1 (C), and Emxl (D) antisense probes. The lateral limit of Vaxl expression (A) apparently abuts the ventrolateral limit of Pax6 strong expression (B) in the lateral LGE. This limit does not correspond to that of the Dlxl (C), which is located in the LGE, or to the ventrolateral limit of Emxl expression (D), which does not extends into the LGE.

Accordingly, the corticostriatal boundary region would comprise at least two zones confined between three distinct limits of gene expression. Ctx, developing cortex; LGE, lateral ganglionic eminence; MGE, medial ganglionic eminence. Scale bar, $1 \mathrm{~mm}$.

\section{DISCUSSION}

The induction and later the regionalization of the rostral neural plate destined to become the brain depends on tissue interactions and genetic regulations distinct from those occurring in more caudal parts of the central nervous system during the early steps of neurulation (see Ruiz i Altaba, 1994; Lumsden and Krumlauf, 1996). In particular, signals from the endomesoderm and from the anterior neural ridge act together to induce and pattern the forebrain (Ang and Rossant, 1993; Bouwmeester et al., 1996; Shimamura and Rubinstein, 1997; Houart et al., 1998). However, the genetic mechanisms occurring within the developing forebrain during induction and specification remain largely obscure. In order to study these mechanisms, early forebrain markers with restricted pattern of expression are necessary. In this context, the Not 1 subfamily of homeobox-containing genes (see Duboule, 1994) is of interest. High sequence homologies and similar patterns of expression of the Notl genes identified in various species, and necessary for axial mesoderm formation (Talbot et al., 1995), attest a high sequence conservation during vertebrate evolution (von Dassow et al., 1993; Stein and Kessel, 1995; Talbot et al., 1995; Stein et al., 1996). No mouse members have been identified to date. Moreover, sequence homologies between the Notl genes (von Dassow et al., 1993; Stein and Kessel, 1995; Talbot et al., 1995; Stein et al., 1996) and the Emx genes, both expressed in the forebrain (Simeone et al., 1992b), suggests that potential new Not- and Emx-related genes could also exist. Furthermore the mouse Emxl and Emx2 genes are required during forebrain formation (Brunelli et al., 1996; Pellegrini et al., 1996; Qiu et al., 1996).

\section{Characterisation of the Vax1 gene}

In order to isolate novel Not- and Emx-related genes, we probed a E14.5 mouse brain cDNA library (Wijnholds et al., 1995) with the chicken Notl homeobox-coding region (Stein and Kessel, 1995) at low stringency and isolated the Vaxl homeobox-containing gene. PCR-based screenings were performed to isolate the putative Xenopus counterpart, XVaxl. The high degree of conservation of the mouse and Xenopus gene sequences (Fig. 1) and expression patterns (compare Figs 3 and 6 to 7) strongly suggests that both genes are orthologous. The Vaxl homeobox amino acid sequence shares high homology with the various members of the Not and Emx gene families (Fig. 1B). However, the YZW amino acid sequence which is present in ems and all Emx genes upstream of the homeobox (Simeone et al., 1992b), is absent from Vaxl (Table 1). The Vaxl gene is thus a putative transcription factor which could accordingly reveal the existence of a new subgroup of homeobox-containing gene family.

The mouse Vaxl gene locus is localized at the very distal end of the mouse chromosome 19 (Fig. 2). Comparison of the position of this locus with that of Pax2, FGF8 and Emx2
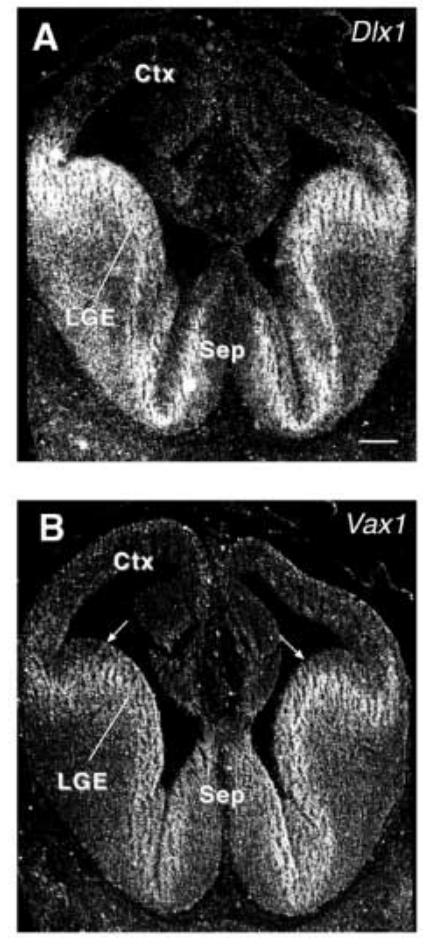

Fig. 10. Pax6 function is necessary to maintain the normal Vax 1 lateral limit of expression in the LGE subventricular zone.

Transverse sections through a homozygous small eye (sey/sey) E13.5 mouse rostral forebrain. (A) Dlxl antisense probe; (B) Vaxl, antisense probe. In the sey/sey brain, the Dlxl expression is no longer confined into the septum and LGE, but extends in the developing cortex (A). As observed in wild-type brains (see Fig. 7B), the Vaxl expression is limited laterally in the ventricular zone of the sey/sey LGE (B, see arrows). Though more limited than that of Dlxl, Vaxl ectopic expression towards the developing cortex also occurs in brains of Pax6-deficient homozygous animals at the level of the subventricular zone. Arrows indicate the lateral limit of Vaxl in the ventricular zone. Ctx, developing cerebral cortex; LGE, lateral ganglionic eminence; Sep, septum. Scale bar, $200 \mu \mathrm{m}$. 
indicates a linkage of the Vaxl and Emx2 loci. The genes may therefore have arisen by a tandem duplication. However, apart from mutations in the EMX2 locus level (Simeone et al., 1992b; Brunelli et al., 1996), no human or mouse disorder consistent with a modification of Vaxl have been mapped at this level.

Similarly to the mouse Emx2 and Vaxl genes, the Drosophila ems and E5 (see Fig. 1B) genes share high sequence homology and identical cytological location in the region 88A of polytene chromosome (Dalton et al., 1989). This could indicate a highly conserved chromosomal organisation in vertebrate and arthropods at that level. However, further functional experiments in both genders are necessary to conclude about possible orthology between these genes.

\section{Possible functions of Vax1}

Mutations of the Drosophila empty spiracles (ems) gene affect embryonic head development and lead to loss of head structures (see Hirth et al., 1995). Therefore, ems acts as both a gap gene, responsible for the formation of group of head segments, and a homeotic selector genes, specifying segment identity (Dalton et al., 1989; Walldorf and Gehring, 1992). Similarly, inactivation of Emx1 or Emx2 murine genes by homologous recombination in the mouse demonstrates that these genes are necessary for the formation of specific regions of the brain where they are expressed and for migration of some cortical neurons (Pellegrini et al., 1996; Qiu et al., 1996; Yoshida et al., 1997). Mutations in the human EMX2 genes have also been identified in patients with holoprosencephaly (Brunelli et al., 1996). Likewise, Notl inactivation in the zebrafish leads to absence of notochord where the gene is normally expressed (Talbot et al., 1995). Vaxl sharing high sequence homology with these genes could accordingly be necessary for ventral forebrain specification and patterning. Moreover, the stability of Vaxl pattern of expression during neurulation in mouse and Xenopus suggests an important function of Vax1 in the specification and maintenance of basal forebrain identity. Vaxl is also expressed in the anterior neural ridge (ANR) (see Figs 3 and 6). This structure has inducing properties on the anterior neural plate mimicked by the FGF8 expressed at this level (Shimamura and Rubinstein, 1997). Vaxl could accordingly participate in early neural plate induction.

During early brain morphogenesis in mouse and Xenopus, Vaxl transcripts are detected in regions that precisely correspond to the derivatives of the area where the gene is expressed at the neural plate stage (Figs 3, 4, 6-8) (Couly and Le Douarin, 1987; Eagleson and Harris, 1990; Eagleson et al., 1995) and indicate that the early Vaxl-expressing region is an embryological unit. This region could correspond to the part of the brain induced in Xenopus by Cerberus and specified by signals from rostral endoderm (Bouwmeester et al., 1996; Thomas and Beddington, 1996).

Vaxl expression is simultaneous with neuronal progenitor proliferation and neural cell specification in the septum, preoptic area (Bayer and Altman, 1987a), and LGE (Fentress et al., 1981; Bayer and Altman, 1987b; Halliday and Cepko, 1992; De Carlos et al., 1996; Szele and Cepko, 1996). In addition, the subventricular zone where Vaxl is expressed in the ganglionic eminences, is considered to be a transition zone that cells, originating in the ventricular zone, cross or where they can further proliferate and acquire information important for their final fate (Boulder Committee, 1970). Furthermore, Vaxl transcription occurring in the medial olfactory placode from E8 to E11 is no longer detected in the olfactory epithelium or in the vomeronasal organ at E13.5 (data not shown). The medial olfactory placode is the site of origin of the vomeronasal organ and of GnRH neurons that leave the placode from E11 onward, migrate out and settle in the septal and preoptic areas (Zheng et al., 1992; Pellier and Astic, 1994; De Carlos et al., 1995; Schwanzel-Fukuda et al., 1996). Accordingly, Vaxl could function in early developing progenitors present in the medial olfactory placode before they migrate to the basal forebrain. In general, Vaxl could thus function in the early steps of the neuronal differentiation.

Moreover, the derivatives of the embryonic brain region expressing Vaxl are widely interconnected and may be considered as a functional unit (Carpenter, 1991) which appeared early in the evolution of vertebrates (Ariëns Kappers et al., 1967; Gans, 1989). Vaxl is thus a marker of a phylogenetically ancient embryological unit, which differentiates in a functionally central part of the forebrain.

\section{Vax1 expression in Pax6-deficient homozygous mutant mice}

Vaxl-expressing regions are apparently adjacent to the regions expressing Pax6 at high level. In particular, at the level of the corticostriatal-boundary of wild-type animals, Pax6 expression occurs at high level in the developing cortex and in the lateral part of the LGE. At this level, Vaxl expression occurs in the medial part LGE, and abuds that of Pax6 laterally. This observation suggests that some cross regulation may occur between these two genes or the regulatory cascades in which they are involved.

Vaxl pattern of expression is modified in Pax6-deficient homozygous mice at the level of the corticostriatal boundary. As already described for Dlxl (Stoykova et al., 1996) at the level of the subventricular zone, Vaxl expression is no longer confined in the LGE, or so-called striatal compartment, but extends towards the cortical area (Fig. 10A). However, the lateral limit of Vaxl expression is still clear-cut in the lateral LGE ventricular zone (see arrows in 10B) and remains more medial than that of Dlxl (Fig. 10A,B). Accordingly, Pax6 is not necessary to restrict Vaxl expression pattern in the LGE ventricular zone. Nevertheless, the ectopic Vaxl expression in the cortical subventricular zone of Pax6-deficient embryos suggests that the Pax 6 gene product maintains and stabilizes the Vaxl expression pattern outside the ventricular zone. Besides, Pax6 regulates forebrain patterning in general by regulating cell adhesion properties in a specific territory (Stoykova et al., 1997) and thereby controlling boundary formation and, as a consequence, the neuromere identification (Mastick et al., 1997). Finally, the cells expressing Vaxl ectopically are no longer located over a ventricular zone also expressing the gene as in the normal situation. It is thus likely that the ectopic expression of Vaxl in these mutants is the consequence of an abnormal cell migration rather than a change of the identity of the lateroventral subventricular cortical compartment. Moreover, the possibility for striatal precursors to differentiate in the cortex has been already documented from grafting experiments (Fishell, 1997), and cell migration of $D l x$-dependent neuroblast from the LGE to the cortex have been characterized (see De Carlos et al., 1996; 
Anderson et al., 1997a,b). These striatocortical routes could accordingly be followed by Vaxl- and Dlxl-expressing cells in Pax6-deficient animals.

\section{The question of the corticostriatal boundary}

Comparison of the limits of the expression territory of Vaxl with that of Dlxl, Pax6 and Emxl indicates that the morphological corticostriatal sulcus does not correspond to a general limit of gene expression (see Puelles and Rubenstein, 1993; Stoykova et al., 1997). Strong Pax6 gene expression occurs in the developing cortex, transgresses the anatomical sulcus and extends in the lateral part of the LGE, the so-called corticostriatal ridge or palliostriatal ventricular angle (Bayer and Altman, 1991). At this level, Pax6 expression is complementary with that of Vaxl, which is confined to the LGE (Figs 7A,B, 9A,B). Additionally, Dlxl expression is also confined to the LGE, but it however extends slightly more distally than Vaxl toward the cortical compartment (Figs 7B,C, 9B,C). Inversely, the Emxl gene expression is strictly limited in the cortical compartment (Fig. 9D). Therefore, the corticostriatal sulcus is a simple anatomically identifiable structure, which does not correspond to a simple frontier for gene expression. Rather, the lateral LGE or palliostriatal ventricular angle is a complex structure with distinct genetic identifiable compartments expressing specific combinations of markers.

Moreover, tritiated thymidine dividing cell labelling demonstrated that endopiriform neurons originate in the palliostriatal ventricular angle (Bayer and Altman, 1991). Similarly, DiI cell labelling experiments demonstrated that the lateral LGE generate neurons of the primary olfactory cortex (De Carlos et al., 1996). Likewise, some cortical neurons producing GABA originate in the LGE, and their differentiation depends on the Dlxl and Dlx2 genes (Anderson et al., 1997a). Vaxl could thus mark a strictly ventral part of the forebrain as opposed to more dorsal parts with cortical fate. Further experiments would be necessary to determine whether some aspects of the cortical development also depend on the activity of the Vaxl gene.

Vaxl transcripts are first present in the most anterior part of the neural plate in mouse and Xenopus. The expression is maintained during early embryonic development in the derivatives of this region. Vaxl therefore marks an embryological unit, being phylogenetically ancient and evolutionary conserved, and which differentiates in a functionally central part of the anterior ventral forebrain. The persistence of Vaxl expression during ontogenesis could suggest a role of $\operatorname{Vaxl}$ in maintaining the identity of this region. Further functional experiments are now in progress to determine the function of this new gene during early forebrain development and neural differentiation. Vaxl should be an interesting tool to study the specification, patterning and terminal differentiation of the forebrain.

We thank A. Simeone for the Emxl probe, L. Saint-Onge and A. Stoykova for the Pax6-deficient mice, A. Stoykova and G. AlvarezBolado for discussions, and F. Guillemot, A. Stoykova and C. Greeds for reading the manuscript. We also thank Debra J. Gilbert and Kirsten Rollert for excellent technical assistance, and Ralf Altschäffel for photographic work. M. H. is particularly grateful to Catherine GuethHallonet for permanent support and encouragement. This research was supported, in part, by the National Cancer Institute, DHHS, under contact with ABL; and by the Max-Planck-Society. M. H. was supported by a TMR grant from the European Commission.

\section{REFERENCES}

Acampora, D., Mazan, S., Lallemand, Y., Avantaggiato, V., Maury, M., Simeone, A. and Brûlet, P. (1995). Forebrain and midbrain regions are deleted in $\operatorname{Otx} 2(-1-)$ mutants due to a defective anterior neuroectoderm specification during gastrulation. Development 121, 3279-3290.

Anderson, S. A., Eisenstat, D. D., Shi, L. and Rubenstein, J. L. R. (1997a), Interneuron migration from the basal forebrain to neocortex: dependence on Dlx genes. Science 278, 474-476.

Anderson, S. A., Mengshen, Q., Bulfone, A., Eisenstat, D. D., Meneses, J., Pedersen, R. and Rubenstein, J. L. R. (1997b). Mutations of the homeobox genes $D l x-1$ and $D l x-2$ disrupt the striatal subventricular zone and differentiation of late born striatal neurons. Neuron 19, 27-37.

Ang, S. L., Conlon, R. A., Jin, O. and Rossant, J. (1994). Positive and negative signals from mesoderm regulate the expression of mouse Otx2 in ectoderm explants. Development 120, 2979-2989.

Ang, S. L., Jin, O., Rhinn, M., Daigle, N., Stevenson, L. and Rossant, J. (1996). A targeted mouse Otx 2 mutation leads to severe defects in gastrulation and formation of axial mesoderm and to deletion of rostral brain. Development 122, 243-252.

Ang, S. L. and Rossant, J. (1993). Anterior mesendoderm induces mouse Engrailed genes in explant cultures. Development 118, 139-149.

Ariëns Kappers, C. U., Huber, G. C. and Crosby, E. C. (1967). The comparative anatomy of the nervous system of vertebrates, including man. New York: Hafner Publishing Company, Inc.

Bayer, S. A. and Altman, J. (1987a). Development of the preoptic area: Time and site of origin, migratory routes, and settling patterns of its neurons. $J$. Comp. Neurol. 265, 65-95.

Bayer, S. A. and Altman, J. (1987b). Directions in neurogenic gradients and pattern of anatomical connections in the telencephalon. Prog. Neurobiol. 29, 57-106.

Bayer, S. A. and Altman, J. (1991). Development of the endopiriform nucleus and the claustrum in the rat brain. Neuroscience 45, 391-412.

Boek, R. and Kolakofsky, D. (1994). Position +5 and +6 can be major determinants of the efficiency of non-AUG initiation codons for protein synthesis. EMBO J. 13, 3608-3617.

Boulder Commitee (1970). Embryonic Vertebrate Central System: Revised Terminology. Anat. Rec. 166, 257-262.

Bouwmeester, T., Kim, S.-H., Sasai, Y., Lu, B. and De Robertis, E. (1996). Cerberus is a head-inducing secreted factor expressed in the anterior endoderm of Spemann's organizer. Nature 382, 595-601.

Brunelli, S., Faiella, A., Capra, V., Nigro, V., Simeone, A., Cama, A. and Boncinelli, E. (1996). Germline mutations in the homeobox gene EMX2 in patients with severe schizencephaly. Nat. Genet. 12, 94-6.

Bulfone, A., Puelles, L., Porteus, M. H., Frohman, M. A., Martin, G. R. and Rubenstein, J. L. R. (1993). Spatially restricted expression of $D l x-1$, Dlx-2 (Tes-1), Gbx-2, and Wnt-3 in the embryonic day 12.5 mouse forebrain defines potential transverse and longitudinal segmental boundaries. $J$. Neurosci. 13, 3155-3172.

Caric, D., Gooday, D., Hill, R. E., McConnell, S. K. and Price, D. J. (1997). Determination of the migratory capacity of embryonic cortical cells lacking the transcription factor Pax-6. Development 124, 5087-5096.

Carpenter, M. B. (1991). Core text of neuroanatomy. Baltimore, MD, USA: Williams \& Wilkins.

Cavener, D. R. and Ray, S. C. (1991). Eukaryotic start and stop translation sites. Nucl. Acids Res. 19, 3185-3192.

Copeland, N. G. and Jenkins, A. G. (1991). Development and applications of a molecular genetic linkage map of the mouse genome. Trends Genet. 7, 113-118.

Couly, G. F. and Le Douarin, N. M. (1987). Mapping of the early neural primordium in quail-chick chimeras. II. The prosencephalic neural plate and neural folds: implications for the genesis of cephalic human congenital abnormalities. Dev. Biol. 120, 198-214.

Dale, J. K., Vesque, C., Lints, T. J., Sampath, T. K., Furley, A., Dodd, J. and Placzek, M. (1997). Cooperation of BMP7 and SHH in the induction of forebrain ventral midline cells by prechordal mesoderm. Cell 90, 257269.

Dalton, D., Chadwick, R. and McGinnis, W. (1989). Expression and embryonic function of empty spiracles: a Drosophila homeobox gene with 
two patterning functions on the anterior-posterior axis of the embryo. Genes Dev. 3, 1940-1956.

De Carlos, J. A., Lopez-Mascaraque, L. and Valverde, F. (1995). The telencephalic vesicles are innervated by olfactory placode-derived cells: a possible mechanism to induce neocortical development. Neuroscience $\mathbf{6 8}$ 1167-1178.

De Carlos, J. A., Lopez-Mascaraque, L. and Valverde, F. (1996). Dynamics of cell migration from the lateral ganglionic eminence in the rat. J. Neurosci. 16, 6146-6156

Doniach, T. (1993). Planar and vertical induction of anteroposterior pattern during the development of the amphibian central nervous system. $J$. Neurobiol. 24, 1256-1275.

Duboule, D. (1994). Guidebook to the Homeobox Genes. Oxford: Sambrook and Tooze publication at Oxford University Press.

Eagleson, G., Ferreiro, B. and Harris, W. A. (1995). Fate of the anterior neural ridge and the morphogenesis of the Xenopus forebrain. J. Neurobiol. 28, 146-158.

Eagleson, G. W. and Harris, W. A. (1990). Mapping of the presumptive brain regions in the neural plate of Xenopus laevis. J. Neurobiol. 21, $427-$ 440 .

Ericson, J., Morton, S., Kawakami, A., Roelink, H. and Jessell, T. M. (1996). Two critical periods of sonic hedgehog signaling required for the specification of motoneuron identity. Cell 87, 661-673.

Fentress, J. C., Stanfield, B. B. and Cowan, W. M. (1981). Observations on the development of the striatum in mice and rats. Anat. Embryol. 163, 275298.

Finkelstein, R. and Boncinelli, E. (1994). From fly head to mammalian forebrain: the story of otd and Otx. Trends Genet. 10, 310-315.

Fishell, G. (1997). Regionalization in the mammalian telensephalon. Curr. Opin. Neurobiol. 7, 62-69.

Gans, C. (1989). Stages in the origin of vertebrates: analysis by means of scenarios. Biol. Rev. Camb. Philos. Soc. 64, 221-268.

Glinka, A., Wei, W., Onichtchouk, D., Blumenstock, C. and Niehrs, C. (1997). Head induction by simultaneous repression of Bmp and Wnt signalling in Xenopus. Nature 389, 517-519.

Halliday, A. L. and Cepko, C. L. (1992). Generation and migration of cells in the developing striatum. Neuron 9, 15-26.

Hamburger, V. (1988). The Heritage of Experimental Embryology. Hans Spemann and the Organizer. Oxford: Oxford University Press.

Harland, R. M. (1991). In situ hybridization: an improved whole-mount method for Xenopus embryos. Methods Cell Biol. 36, 685-695.

Hirth, F., Therianos, S., Loop, T., Gehring, W. J., Reichert, H. and Furukubo-Tokunaga, K. (1995). Developmental defects in brain segmentation caused by mutations of the homeobox genes orthodenticle and empty spiracles in Drosophila. Neuron 15, 769-778.

Hogan, B. L. M., Horsburgh, G., Cohen, J., Hetherington, C. M., Fisher, G. and Lyon, M. F. (1986). Small eyes (Sey): a homozygous lethal mutation on chromosome 2 which affects the differentiation of both lens and nasal placodes in the mouse. J. Embryol. exp. Morph. 97, 95-110.

Hollemann, T., Bellefroid, E. and Pieler, T. (1998) The Xenopus homologue of the Drosophila gene tailless has a function in early eye development. Development 125, 2425-2432.

Houart, C., Westerfield, M. and Wilson, S. W. (1998). A small population of anterior cells patterns the forebrain during zebrafish gastrulation. Nature 391, 788-792.

Israel, D. I. (1993). A PCR-based method for high stringency screening of DNA libraries. Nucleic Acid Res. 21, 2627-2631.

Jenkins, N. A., Copeland, N. G., Taylor, B. A. and Lee, B. K. (1982) Organization, distribution, and stability of endogenous ecotopic murine leukemia virus DNA sequences in chromosomes of Mus musculus. J. Virol. 43, 26-36

Juan, T. S.-C., McNiece, I. K., Argento, J. M., Jenkins, N. A., Gilbert, D. J. and Copland, N. G. (1997). Identification and mapping of Casp7, a cystein protease resembling CPP32beta, interleukin-1beta converting enzyme, and CED-3. Genomics 40, 86-93.

Kastury, K., Druck, T., Huebner, K., Barletta, C., Acampora, D., Simeone, A., Faiella, A. and Boncinelli, E. (1994). Chromosome locations of human EMX and OTX genes. Genomics 22, 41-45.

Kozak, M. (1986). Point mutations define a sequence flanking the AUG initiator codon that modulates translation by eukaryotic ribosomes. Cell $\mathbf{4 4}$, 283-292.

Krumlauf, R., Marshall, H., Studer, M., Nonchev, S., Sham, M. H. and Lumsden, A. (1994). Hox homeobox genes and regionalisation of the nervous system. J. Neurobiol. 24, 1328-1340.
Lufkin, T. (1996). Transcriptional control of Hox genes in vertebrate nervous system. Curr. Opin. Genet. Dev. 6, 575-580.

Lumsden, A. and Krumlauf, R. (1996). Patterning the vertebrate neuraxis. Science 274, 1109-1115.

Mastick, G. S., Davis, N. M., Andrews, G. L. and Easter Jr, S. S. (1997). Pax 6 functions in boundary formation and axon guidance in the embryonic mouse forebrain. Development 124, 1985-1997.

Matsuo, I., Kuratani, S., Kimura, C., Takeda, N. and Aizawa, S. (1995) Mouse Otx2 functions in the formation and patterning of rostral head. Genes Dev. 9, 2646-2658.

Matsuo, T., Osumi-Yamashita, N., Noji, S., Ohuchi, H., Koyama, E., Myokai, F., Matsuo, N., Taniguchi, S., Doi, H., Ninomiya, Y., Fujiwara, M., Watanabe, T. and Eto, K. (1993). A mutation in the Pax-6 gene in rat small eye is associated with impaired migration of midbrain crest cells. Nature Genet. 3, 299-304.

Oliver, G., Mailhos, A., Wehr, R., Copeland, N. G., Jenkins, N. A. and Gruss, P. (1995). Six3, a murine homologue of the sine oculis gene, demarcates the most anterior border of the developing neural plate and is expressed during eye development. Development 121, 4045-55.

Pannese, M., Polo, C., Andreazzoli, M., Vignali, R., Kablar, B., Barsacchi, G. and Boncinelli, E. (1995). The Xenopus homologue of Otx2 is a maternal homeobox gene that demarcates and specifies anterior body regions. Development 121, 707-720.

Pellegrini, M., Mansouri, A., Simeone, A., Boncinelli, E. and Gruss, P. (1996). Dentate gyrus formation requires Emx2. Development 122, 3893 3898.

Pellier, V. and Astic, L. (1994). Histochemical and immunocytochemical study of the migration of neurons from the rat olfactory placode. Cell Tissue Research 275, 587-598.

Price, M., Lemaistre, M., Pischetola, M., Di Lauro, R. and Duboule, D. (1991). A mouse gene related to Distal-less shows a restricted expression in the developing forebrain. Nature 351, 748-751.

Puelles, L. and Rubenstein, J. L. R. (1993). Expression patterns of homeobox and other putative regulatory genes in the embryonic mouse forebrain suggests a neuromeric organization. Trends Neurosci. 16, 472-479.

Qiu, M., Anderson, S., Chen, S., Meneses, J. J., Hevner, R., Kuwana, E., Pedersen, R. A. and Rubenstein, J. L. R. (1996). Mutation of the Emx-1 homeobox gene disruptd the corpus callosum. Dev. Biol. 178, 174-178.

Roberts, R. C. (1967). Small-eyes, a new dominant mutant in the mouse Genet. Res. 9, 121-122.

Ruiz i Altaba, A. (1994). Pattern formation in the vertebrate neural plate Trends Neurosci. 17, 233-243.

Saha, M. S. and Grainger, R. M. (1992). A labile period in the determination of the anterior-posterior axis during early neural development in Xenopus. Neuron 8, 1003-1014.

Schwanzel-Fukuda, M., Crossin, K. L., Pfaff, D. W., Bouloux, P. M. G., Hardelin, J. P. and Petit, C. (1996). Migration of luteinizing hormonereleasing hormone (LHRH) neurons in early human embryos. J. Comp Neurol. 366, 547-557.

Shawlot, W. and Behringer, R. R. (1995). Requirement for Lim1 in headorganizer function. Nature $\mathbf{3 7 4}, 425-430$.

Shimamura, K. and Rubinstein, J. L. R. (1997). Inductive interactions direct early regionalization of the mouse forebrain. Development 124, 2709-2718.

Simeone, A., Acampora, D., Gulisano, M., Stornaiuolo, A. and Boncinelli, E. (1992a). Nested expression domains of four homeobox genes in developing rostral brain. Nature 358, 687-690.

Simeone, A., Acampora, D., Mallamaci, A., Stornaiuolo, A., D’Apice, M R., Nigro, V. and Boncinelli, E. (1993). A vertebrate gene related to orthodenticle contains a homeodomain of the bicoid class and demarcates anterior neuroectoderm in the gastrulating mouse embryo. EMBO J. 12, 2735-2747.

Simeone, A., Gulisano, M., Acampora, D., Stornaiuolo, A., Rambaldi, M. and Boncinelli, E. (1992b). Two vertebrate homeobox genes related to the Drosophila empty spiracles gene are expressed in the embryonic cerebral cortex. EMBO J. 11, 2541-2550.

Spemann, H. and Mangold, H. (1924). Über die Induktion von Embryoanlagen durch Implantation artfremder Organisatoren. Roux Arch. EntwMech. Org. 100, 599-638.

St-Onge, L., Sosa-Pineda, B., Chowdhury, K., Mansouri, A. and Gruss, P. (1997). Pax6 is required for differentiation of glucagon-producing alphacells in mouse pancreas. Nature 387, 406-409.

Stein, S. and Kessel, M. (1995). A homeobox gene involved in node, notochord and neural plate formation of chick embryos. Mech. Dev. 49, 3748 . 
Stein, S., Niss, K. and Kessel, M. (1996). Differential activation of the clustered homeobox genes CNOT2 and CNOT1 during notogenesis in the chick. Dev. Biol. 180, 519-533.

Stoykova, A., Fritsch, R., Walther, C. and Gruss, P. (1996). Forebrain patterning defects in Small eye mutant mice. Development 122, 3453-3465.

Stoykova, A., Götz, M., Gruss, P. and Price, J. (1997). Pax6-dependent regulation of adhesive patterning, $R$-cadherin expression and boundary formation in developing forebrain. Development 124, 3765-3777.

Stoykova, A. and Gruss, P. (1994). Roles of Pax-genes in developing and adult brain as suggested by expression patterns. J. Neurosci. 14, 13951412.

Szele, F. G. and Cepko, C. L. (1996). A subset of clones in the chick telencephalon arranged in rostrocaudal arrays. Current Biol. 6, 1685-1690.

Talbot, W. S., Trevarrow, B., Halpern, M. E., Melby, A. E., Farr, G., Postlethwait, J. H., Jowett, T., Kimmel, C. B. and Kimelman, D. (1995). A homeobox gene essential for zebrafish notochord development. Nature 378, 150-157.

Thomas, P. and Beddington, R. (1996). Anterior primitive endoderm may be responsible for patterning the anterior neural plate of the mouse embryo. Current Biol. 6, 1487-1496.

Thor, T. (1995). The genetics of brain development: Conserved programs in flies and mice. Neuron 15, 975-977. von Dassow, G., Schmidt, J. E. and Kimelman, D. (1993). Induction of the Xenopus organizer: expression and regulation of Xnot, a novel FGF and activin-regulated homeo box gene. Genes Dev. 7, 355-366.

Walldorf, U. and Gehring, W. J. (1992). Empty spiracles, a gap gene containing a homeobox involved in Drosophila head development. EMBO J. 11, 2247-2259.

Walther, C. and Gruss, P. (1991). Pax-6, a murine paired box gene, is expressed in the developing CNS. Development 113, 1435-1449.

Warren, N. and Price, D. J. (1997). Roles of Pax-6 in murine diencephalic development. Development 124, 1573-1582.

Wijnholds, J., Chowdhury, K., Wehr, R. and Gruss, P. (1995). Segment specific expression of the neuronatin gene during early hindbrain development. Dev. Biol. 171, 73-84.

Wilkinson, D. G. (1992). In Situ Hybridization: A Practical Approach Oxford: IRL Press.

Yoshida, M., Suda, Y., Matsuo, I., Miyamoto, N., Takeda, N., Kuratani, S. and Aizawa, S. (1997). Emxl and Emx2 functions in development of dorsal telencephalon. Development 124, 101-111.

Zheng, L. M., Pfaff, D. W. and Schwanzel-Fukuda, M. (1992). Electron microscopic identification of luteinizing hormone-releasing hormoneimmunoreactive neurons in the medial olfactory placode and basal forebrain of embryonic mice. Neuroscience 46, 407-418. 